\title{
CLERODANE DITERPENES FROM LEAVES OF Casearia sylvestris SWARTZ
}

\author{
André G. dos Santos, Carla C. Perez, Aristeu G. Tininis, Vanderlan da S. Bolzani and Alberto J. Cavalheiro* \\ Instituto de Química de Araraquara, Universidade Estadual Paulista "Júlio de Mesquita Filho", R. Francisco Degni, s/n, \\ 14800-900 Araraquara - SP, Brasil
}

Recebido em 18/4/06; aceito em 10/11/06; publicado na web em 17/7/07

\begin{abstract}
Ethanolic extracts of the leaves of Casearia sylvestris yielded a novel clerodane diterpene, 15-hydroxy-3-cleroden-2-one, together with the known diterpenes (-)-hardwickiic acid, reported for the first time from this species, and casearins B and G, previously isolated from $C$. sylvestris. The structures of all four compounds were determined by spectrometric analysis. The new clerodane diterpene and (-)-hardwickiic acid contain structural features that are completely different from the highly oxygenated casearins and casearvestrins isolated from C. sylvestris.
\end{abstract}

Keywords: Casearia sylvestris; clerodane diterpenes; 15-hydroxy-3-cleroden-2-one.

\section{INTRODUCTION}

Casearia sylvestris Swartz (Flacourtiaceae) is a tree that is widely distributed within various ecosystems of South America, such as the Cerrado and the Atlantic and Amazon forests ${ }^{1}$. In the popular medicine of Brazil, the use of the plant ${ }^{1}$ is correlated with its pharmacological properties including anti-inflammatory ${ }^{2}$, antiophidian $^{2,3}$ and anti-ulcer ${ }^{1,4}$ activities. A number of phytochemical investigations of species of Casearia $^{5-9}$ have revealed the occurrence within the genus of oxygenated tricyclic clerodane diterpenes exhibiting a cis configuration between rings $\mathrm{A}$ and $\mathrm{B}$ and a characteristic diacetal system in ring $\mathrm{C}$ at positions $\mathrm{C}-18$ and $\mathrm{C}-19$. Several compounds of this type have been isolated from $C$. sylvestris, specifically casearins and casearvestrins, and they exhibited cytotoxic activity ${ }^{5,7-9}$.

This paper describes the isolation and structure elucidation of a novel clerodane diterpene, 15-hydroxy-3-cleroden-2-one (1), from the leaves of $C$. sylvestris, together with (-)-hardiwickiic acid (2), reported for the first time from this species. In addition, casearin $B$ (3) and G (4) were isolated, diterpenes that have been previously detected in the species ${ }^{5,7,8}$. The structures of compounds 1-4 (Figure 1) were deduced on the basis of their spectral data and comparison with appropriate values reported in the literature.

\section{RESULTS AND DISCUSSION}

Ethanol extract of the leaves of $C$. sylvestris was submitted to chromatographic fractionation and yielded compounds 1-4. In the positive-ion mode, the HRTOF-ESIMS of $\mathbf{1}$ exhibited an $[\mathrm{M}+\mathrm{Na}]^{+}$ ion at $\mathrm{m} / \mathrm{z} 329.2481$ that was compatible with a molecular formula of $\mathrm{C}_{20} \mathrm{H}_{34} \mathrm{O}_{2}$. Analysis of the PND and DEPT $135^{\circ}{ }^{13} \mathrm{C}$-NMR spectra of $\mathbf{1}$ revealed twenty signals similar to those of the clerodane diterpene skeleton ${ }^{6-11}$, being five of them attributed to methyl groups: C-16 ( $\delta$ 19.7), C-17 ( $\delta 16.0)$, C-18 ( $\delta 20.5), C-19$ ( $\delta 32.2)$, C-20 ( $\delta$ 19.3). The IR and UV absorptions at $1653 \mathrm{~cm}^{-1}$ and at $218 \mathrm{~nm}$ $\left(\lambda_{\max }\right)$ and the NMR signals at $\delta 199.3$ (C-2), 128.6 (C-3), 168.5 (C-4) and 5.84 br s (H-3) indicated the presence of an $\alpha, \beta$ unsaturated ketone group. In addition, the IR absorption at 3448 $\mathrm{cm}^{-1}$ and the NMR signals observed at $\delta 61.2(\mathrm{C}-15)$ and $3.68 \mathrm{~m}$

*e-mail: albjcava@iq.unesp.br

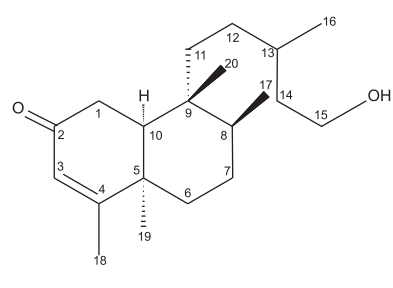

1

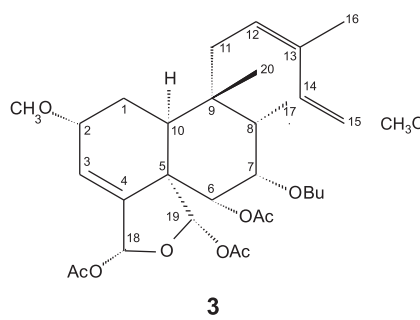

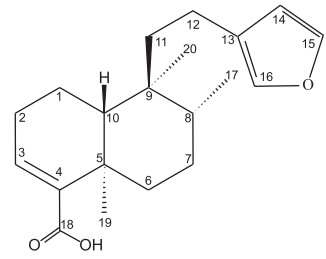

2

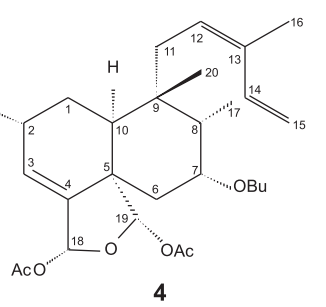

Figure 1. Structures of 15-hydroxy-3-cleroden-2-one (1), (-)-hardiwickiic acid (2), casearin B (3) and casearin G (4): AcO-acetate, BuO-butanoate

(H-15) are characteristic of a hydroxymethine group. The ${ }^{1} \mathrm{H}$ NMR and ${ }^{13} \mathrm{C}$ assignments (Table 1) together with the results of HMQC, COSY and HMBC (Figure 2) experiments led to structure of compound 1. The relative configuration assignment at C-5, C-8, C9 and $\mathrm{C}-10$ was firstly proposed based on comparison of chemical shifts of methyl groups C-17, C-19 and C-20 of compound 1 with literature data, as follow. The cis stereochemistry at the junction of rings $\mathrm{A}$ and $\mathrm{B}$ in compound $\mathbf{1}$ could be deduced from the chemical shift of C-19 ( $\delta 32.2)$ when compared with C-19 chemical shifts of cis-clerodane diterpenes, for example floridiolic acid ${ }^{12}$ and 13hydroxy-cis-ent-cleroda-3,14-diene ${ }^{13}$ ( $\delta 33.6$ and 33.0 , respectively). In contrast, the trans-clerodane diterpenes 2-oxokolavenic acid ${ }^{10}$ and eremone ${ }^{11}$ presented chemical shifts for this methyl carbon at $\delta 19.5$ and 18.8 , respectively. In clerodane diterpenes with a cis configuration between methyl groups C-17 and C-20, such as hautriwaic acid ${ }^{11}, 2$-oxokolavenic acid ${ }^{10}$ and floridiolic acid ${ }^{12}$, the chemical shift of C-20 was observed at approximately $\delta 18.0$, whilst clerodane diterpenes with a trans configuration between these methyl groups, as in the casearins and casearvestrins ${ }^{5-9}$, show chemical shift for C-20 at approximately $\delta 26.0$. So, the chemical shifts attributed to C-20 in compound $\mathbf{1}$ (19.3) is indicative of a cis 
relationship between these methyl groups. These propositions were confirmed by the NOE enhancements arising from the dipolar interactions between $\mathrm{H}-19(1.22 s)$ and $\mathrm{H}-10(1.87 \mathrm{br} d ; 6.5 \mathrm{~Hz})$ and between $\mathrm{H}-17(0.77 d ; 7.0 \mathrm{~Hz})$ and $\mathrm{H}-20(0.57 s)$. In addition, correlations observed in the NOE experiments (Figure 3 ) between $\mathrm{H}-1 \alpha(\delta 2.71)$ and $\mathrm{H}-19$ and between $\mathrm{H}-1 \beta$ and $\mathrm{H}-20$, revealed the trans relationship between $\mathrm{C}-17 / \mathrm{C}-20$ and $\mathrm{C}-19$ methyl groups. A diastereomer of compound $\mathbf{1}$ was previously isolated from Cistus populifolius $\mathrm{L}$. (Cistaceae) $)^{14}$, but the ${ }^{13} \mathrm{C}$ NMR data of this compound were not included in the article to a complete comparison.

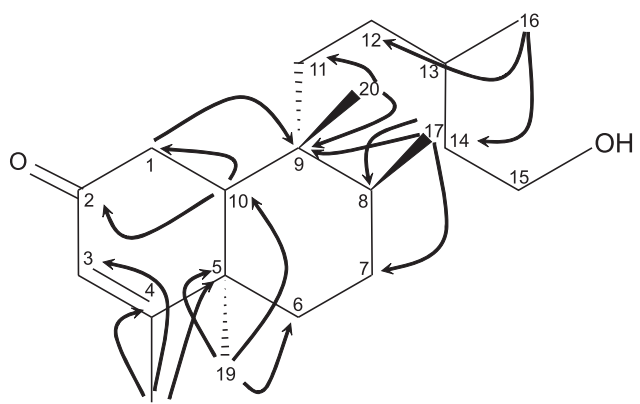

Figure 2. Selected correlations observed in the HMBC spectra of 15-hydroxy3-cleroden-2-one $(\mathbf{1}):(H \rightarrow C)$

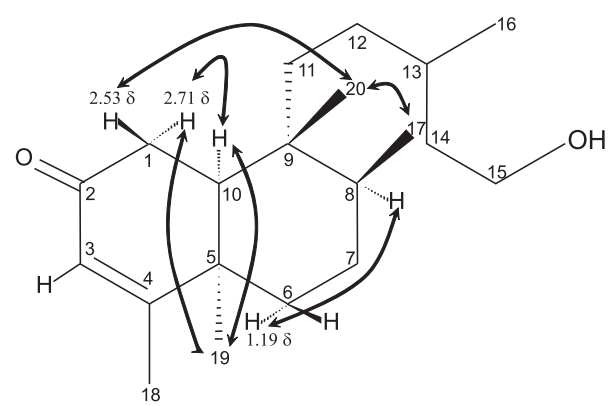

Figure 3. Selected correlations observed by NOE difference and NOESY spectroscopy of 15-hydroxy-3-cleroden-2-one (1)

In the positive-ion mode, the HRTOF-ESIMS of compound 2 exhibited an $[\mathrm{M}+\mathrm{H}]^{+}$ion at $m / z$ 317.2117, compatible with a molecular formula of $\mathrm{C}_{20} \mathrm{H}_{28} \mathrm{O}_{3}$, which was confirmed by the finding of $[\mathrm{M}+\mathrm{Na}]^{+}$ion at $\mathrm{m} / z, 339.1963$. Analysis of the PND ${ }^{13} \mathrm{C}-\mathrm{NMR}$ spectra revealed twenty signals similar to those of the clerodane diterpene skeleton ${ }^{6-11}$ and showed the presence of three methyl groups: C-17 ( $\delta$ 16.0), C-19 ( $\delta$ 20.6) and C-20 ( $\delta$ 18.3). IR absorptions presented at $3397 \mathrm{~cm}^{-1}$ and $1684 \mathrm{~cm}^{-1}$, UV absorption $\left(\lambda_{\max }\right)$ at $210 \mathrm{~nm}$ and the signals observed in the ${ }^{13} \mathrm{C}$-NMR spectra at $\delta 172.5(\mathrm{C}-18), 140.2(\mathrm{C}-3)$ and $141.5(\mathrm{C}-4)$ were indicative of an $\alpha, \beta$-unsaturated carboxylic group. In addition, the ${ }^{1} \mathrm{H}$ and ${ }^{13} \mathrm{C}$ NMR spectra showed signals that could be ascribed to a $\beta$-monosubstituted furan ring (C-13, C-14, C-15 and C-16) in the lateral chain of the diterpene. The complete attribution of the NMR signals (table 1) was based on the correlations observed in the HMQC, HMBC and COSY contour plots and this attribution is in agreement with the NMR data from literature for hardiwickiic acid ${ }^{15}$. The negative value of $[\alpha]_{\mathrm{D}}^{25}$ confirmed the absolute configuration as (-)-hardiwickiic acid ${ }^{16}$. Compound 2 or its enantiomer were previously isolated from other species of different families, as Copaifera duckei, C. guianensis, Croton californicus, C. aromaticus, Hardwickia pinnata, Salvia divinorum and Sindora sumatrana ${ }^{15,17}$, and now we found it for the first time in a Casearia species.

The ${ }^{1} \mathrm{H}$ - and ${ }^{13} \mathrm{C}$-NMR data of $\mathbf{3}\left(\mathrm{C}_{31} \mathrm{H}_{44} \mathrm{O}_{10}\right)$ and $\mathbf{4}\left(\mathrm{C}_{29} \mathrm{H}_{42} \mathrm{O}_{8}\right)$ showed signals identical of the compounds previously reported in C. sylvestris ${ }^{5,7,8}$, casearins $\mathrm{B}$ and $\mathrm{G}$, respectively.

\section{EXPERIMENTAL}

\section{General}

Column chromatography (CC) and solid phase extraction (SPE) were performed over activated charcoal (Synth), silica gel G (40$63 \mu \mathrm{m}$; Merck) or RP-C18 (40-63 $\mu \mathrm{m}$; Merck) and the resulting fractions were monitored by TLC, HPLC-UV and ${ }^{1} \mathrm{H}-\mathrm{NMR}$. Comparative TLC was carried out on silica gel G60 layers $(0.25$ $\mathrm{mm}$ thickness; Merck). HPLC-UV analyses were conducted using a Supelcosil LC-18 column $(250$ x $4.6 \mathrm{~mm}$; i.d. $5 \mu \mathrm{m})$ connected to a Varian chromatographic system consisting of a ProStar 240 solvent delivery module, a ProStar 330 photodiode array detector, a ProStar 410 autosampler and a Star chromatography workstation. For preparative HPLC, a Supelcosil PLC-18 column (250 x $21.2 \mathrm{~mm}$; i.d. $12 \mu \mathrm{m}$ ) was coupled to a Varian system consisting of Dynamax model Sd-1 solvent delivery system and a ProStar 320 detector with Star integrator software.

IR spectra ( $\mathrm{KBr}$ disc) were obtained using a Perkin Elmer FTIR 1600 spectrometer, UV spectra were measured on a Cary $13 \mathrm{E}$ instrument and a Perkin Elmer 341 polarimeter was employed to determine optical activities. NMR spectra of $\mathbf{1}$ and $\mathbf{2}$ were recorded at 500 and $125 \mathrm{MHz}$ for ${ }^{1} \mathrm{H}$ - and ${ }^{13} \mathrm{C}-\mathrm{NMR}$, respectively, using a Varian INOVA 500 spectrometer with $\mathrm{CHCl}_{3}$ as internal standard. The NMR spectra of $\mathbf{3}$ and $\mathbf{4}$ were measured at 200 and $50 \mathrm{MHz}$ for ${ }^{1} \mathrm{H}$ - and ${ }^{13} \mathrm{C}-\mathrm{NMR}$, respectively, on a Bruker AC-200 instrument using the same internal standard. Accurate-mass measurements were performed on an ESI-quadrupole-time of flight instrument (UltrOTOF $_{Q}$, Bruker Daltonics, Billerica, MA).

\section{Plant material}

Leaves of Casearia sylvestris Swartz (Flacourtiaceae) were collected at the Carlos Botelho State Park (São Paulo State, Brazil) and in Araraquara (São Paulo State, Brazil) between August and November 1999. Voucher specimens (AGS13 and AGS45) are deposited at the State Herbarium "Maria Eneida P. Kaufmann" of the Botanic Institute (São Paulo State, Brazil).

\section{Extraction and isolation of 1, 3 and 4}

Dried and powdered leaves of $C$. sylvestris $(2.1 \mathrm{~kg})$ were extracted by sonication with EtOH ( 3 x $6.0 \mathrm{~L} ; 20$ min per extraction) and concentrated under reduced pressure to yield $139.0 \mathrm{~g}$ of residue. The crude extract was partitioned between $\mathrm{MeOH}$ :water (7:3, v/v, $0.8 \mathrm{~L})$ and $\mathrm{CH}_{2} \mathrm{Cl}_{2}(1.5 \mathrm{~L})$ and the $\mathrm{CH}_{2} \mathrm{Cl}_{2}$ layer separated, dried and concentrated under reduced pressure to yield $71.0 \mathrm{~g}$ of a residue that was subjected to SPE over silica gel eluted sequentially with $\mathrm{CH}_{2} \mathrm{Cl}_{2}, \mathrm{CH}_{2} \mathrm{Cl}_{2}: \mathrm{MeOH}(9: 1)$ and $\mathrm{MeOH}$, yielding 8 fractions. SPEfraction 5 (13.5 g) eluted with $\mathrm{CH}_{2} \mathrm{Cl}_{2}: \mathrm{MeOH}$ (9:1) was submitted to $\mathrm{CC}$ over silica gel eluted sequentially with hexane:EtOAc $(8: 2$, 6:4 and 4:6), EtOAc, EtOAc:MeOH (9:1) and $\mathrm{MeOH}$, yielding 12 CC-fractions. CC-fraction 8 (1.45 g) eluted with hexane:EtOAc 4:6 was submitted to RP-CC over octadecyl silane eluted sequentially with $\mathrm{MeOH}$ :water (6:4, 8:2 and 9.5:0.5), $\mathrm{MeOH}$ and $\mathrm{CH}_{2} \mathrm{Cl}_{2}$. Sub-fraction 3 (120.0 mg) eluted with $\mathrm{MeOH}$ :water 8:2 was submitted to preparative RP-HPLC (C-18, 65\% MeOH, isocratic mode, flow rate $13.0 \mathrm{~mL} / \mathrm{min}, \lambda 235 \mathrm{~nm})$ to yield $\mathbf{1}(5.0$ $\mathrm{mg})$. Further, CC-fraction 7 (2.4 g) eluted with hexane:EtOAc 6:4 was submitted to preparative RP-HPLC (C-18, 75\% MeOH, 
Table 1. ${ }^{13} \mathrm{C}$ - and ${ }^{1} \mathrm{H}-\mathrm{NMR}$ data for 15 -hydroxy-3-cleroden-2-one (1) and (-)-hardwickiic acid (2)

\begin{tabular}{|c|c|c|c|c|}
\hline \multirow[t]{3}{*}{ Position } & \multicolumn{2}{|c|}{ 15-Hydroxy-3-cleroden-2-one (1) } & \multicolumn{2}{|c|}{ (-)-Hardwickiic acid (2) } \\
\hline & ${ }^{13} \mathrm{C}-\mathrm{NMR}{ }^{\text {a }}$ & ${ }^{1} \mathrm{H}-\mathrm{NMR}{ }^{\mathrm{b}}$ & ${ }^{13} \mathrm{C}-\mathrm{NMR}$ a & ${ }^{1} \mathrm{H}-\mathrm{NMR}{ }^{\mathrm{b}}$ \\
\hline & $\delta_{\mathrm{C}}(\mathrm{ppm})$ & $\delta_{\mathrm{H}}(\mathrm{ppm}) J(\mathrm{~Hz})$ & $\delta_{\mathrm{C}}(\mathrm{ppm})$ & $\delta_{\mathrm{H}}(\mathrm{ppm}) J(\mathrm{~Hz})$ \\
\hline \multirow[t]{2}{*}{1} & $35.5 t$ & $2.53 d(19.0)$ & $17.5 t$ & $1.70 \mathrm{~m}$ \\
\hline & & $2.71 d d(19.0,6.5)$ & & \\
\hline 2 & $199.3 s$ & - & $27.3 t$ & $1.42 \mathrm{~m}$ \\
\hline 3 & $128.6 d$ & $5.84 b r s$ & $140.2 d$ & $6.82 d d(4.5,3.0)$ \\
\hline 4 & $168.5 s$ & -- & $141.5 s$ & - \\
\hline 5 & $39.3 s$ & -- & $37.6 \mathrm{~s}$ & - \\
\hline \multirow[t]{2}{*}{6} & $36.9 t$ & $1.19 \mathrm{~m}$ & $35.9 t$ & $2.40 d t(13.0,3.0)$ \\
\hline & & $2.09 \mathrm{~m}$ & & $1.17 \mathrm{td}(13.0,4.0)$ \\
\hline 7 & $28.4 t$ & $1.34 \mathrm{~m}$ & $27.5 t$ & $n r^{*}$ \\
\hline 8 & $36.6 d$ & $1.48 \mathrm{~m}$ & $36.3 d$ & $n r^{*}$ \\
\hline 9 & $40.1 s$ & $3 / 4$ & $38.9 s$ & - \\
\hline 10 & $47.2 d$ & $1.87 \mathrm{brd}(6.5)$ & $46.7 d$ & $1.36 d d(11.0,1.0)$ \\
\hline \multirow[t]{2}{*}{11} & $33.8 t$ & $1.18 \mathrm{~m}$ & $38.7 t$ & $1.52 \mathrm{~m}$ \\
\hline & & $1.42 \mathrm{~m}$ & & $1.64 \mathrm{~m}$ \\
\hline \multirow[t]{2}{*}{12} & $29.7 t$ & $0.94 m$ & $18.2 t$ & $n r^{\mathrm{c}}$ \\
\hline & & $1.24 \mathrm{~m}$ & & $n r^{\mathrm{c}}$ \\
\hline 13 & $30.2 d$ & $n r^{\mathrm{c}}$ & $125.6 s$ & - \\
\hline \multirow[t]{2}{*}{14} & $40.0 t$ & $1.38 \mathrm{~m}$ & $111.0 d$ & $6.23 d d(2.0,1.0)$ \\
\hline & & $1.61 \mathrm{~m}$ & & \\
\hline 15 & $61.2 t$ & $3.68 \mathrm{~m}$ & $142.7 d$ & $7.32 t(2.0)$ \\
\hline 16 & $19.7 q$ & $0.91 d(7.0)$ & $138.4 d$ & $7.18 m$ \\
\hline 17 & $16.0 q$ & $0.77 d(7.0)$ & $16.0 q$ & $0.81 d(6.5)$ \\
\hline 18 & $20.5 q$ & $1.94 d(1.5)$ & $172.5 s$ & - \\
\hline 19 & $32.2 q$ & $1.22 \mathrm{~s}$ & $20.6 q$ & $1.24 s$ \\
\hline 20 & $19.3 q$ & $0.57 s$ & $18.3 q$ & $0.74 \mathrm{~s}$ \\
\hline
\end{tabular}

${ }^{\text {a }}$ Measured in $\mathrm{CDCl}_{3}$ at $125 \mathrm{MHz} ;{ }^{\mathrm{b}}$ Measured in $\mathrm{CDCl}_{3}$ at $500 \mathrm{MHz} ;{ }^{\mathrm{c}} n r$ - not resolved due to overlapping of signals

isocratic mode, flow rate $10.0 \mathrm{~mL} / \mathrm{min}, \lambda 235 \mathrm{~nm})$, yielding compounds $3(86.2 \mathrm{mg})$ and $\mathbf{4}(30.9 \mathrm{mg})$.

\section{Extraction and isolation of 2}

Dried and powdered leaves of $C$. sylvestris $(2.0 \mathrm{~kg})$ were extracted by maceration under agitation with $\mathrm{EtOH}(3 \times 3.0 \mathrm{~L} ; 2 \mathrm{~h}$ per extraction) and concentrated under reduced pressure to yield $190.0 \mathrm{~g}$ of residue. The crude extract was partitioned between EtOH/ Water $(6: 4, v / v, 1.5 \mathrm{~L})$ and hexane $(1.5 \mathrm{~L})$, and the hexane layer separated, dried and concentrated under reduced pressure to yield $120.2 \mathrm{~g}$ of a residue that was subjected to SPE over silica gel:activated charcoal (1:1) eluted sequentially with hexane:EtOAc (7:3 and 3:7) and $\mathrm{MeOH}$. The fraction eluted with hexane/EtOAc 3:7 (28.4 g) was submitted to CC over silica gel eluted sequentially with hexane:EtOAc (7:3, 6:4, 1:1, 4:6 and 3:7) and EtOAc, yielding 24 fractions. Fraction $11(34.0 \mathrm{mg})$ eluted with hexane:EtOAc 1:1 was submitted to SPE over RP-C18 eluted with $\mathrm{MeOH}$ :water (98:2) to yield 2 (29.0 $\mathrm{mg})$.

\section{5-hydroxy-3-cleroden-2-one (1)}

White powder $(5.0 \mathrm{mg})$. $[\alpha]_{\mathrm{D}}{ }^{20}+42^{\circ}(c 0.14 ; \mathrm{MeOH})$. UV $\lambda_{\mathrm{m}}$ $\mathrm{nm}(\mathrm{MeOH}) 218\left(\varepsilon=10.5 \times 10^{3} \mathrm{~cm}^{3} \mathrm{~mol}^{-1} \mathrm{~cm}^{-1}\right)$. IR $v_{\text {max }} \mathrm{cm}^{-1} 3448$, 2958-2853, 1653, 1037 (KBr). ${ }^{1} \mathrm{H}$ - and ${ }^{13} \mathrm{C}-\mathrm{NMR}$ see Table 1. HRTOF-ESIMS $\mathrm{m} / \mathrm{z} 329.2481[\mathrm{M}+\mathrm{Na}]^{+}$(calcd for $\mathrm{C}_{20} \mathrm{H}_{34} \mathrm{O}_{2} \mathrm{Na}^{+}$, 329.2451).

\section{(-)-Hardiwickiic acid (2)}

White powder (29.0 mg). $[\alpha]_{\mathrm{D}}^{25}-35^{\circ}(c 1.0 ; \mathrm{MeOH}) . \mathrm{UV} \lambda_{\max }$ $\mathrm{nm}(\mathrm{MeOH}) 210\left(\varepsilon=7.2 \times 10^{3} \mathrm{~cm}^{3} \mathrm{~mol}^{-1} \mathrm{~cm}^{-1}\right)$. IR $v_{\max } \mathrm{cm}^{-1} 3397$, 2958-2864, 1684, 1640, 1257, $1078(\mathrm{KBr}) .{ }^{1} \mathrm{H}-$ and ${ }^{\max } \mathrm{C}-\mathrm{NMR}$ see
Table 1. HRTOF-ESIMS $m / z, 317.2117[\mathrm{M}+\mathrm{H}]^{+}\left(\right.$calcd for $\mathrm{C}_{20} \mathrm{H}_{29} \mathrm{O}_{3}$, 317.2117 ) and $\mathrm{m} / \mathrm{z}, 339.1963[\mathrm{M}+\mathrm{Na}]^{+}$(calcd for $\mathrm{C}_{20} \mathrm{H}_{28} \mathrm{O}_{3} \mathrm{Na}^{+}$, 339.1930).

\section{CONCLUSIONS}

The new compound (+)-15-hydroxy-3-cleroden-2-one (1) and (-)-hardwickiic acid (2) are the first diterpenes reported in $C$. sylvestris without the typical highly oxygenated backbone. Casearins and casearvestrins, previously isolated from this species, have common stereochemical features of a cis-clerodane diterpene, notably a cis configuration at the junction of rings $\mathrm{A}$ and $\mathrm{B}$ and, in addition, trans configuration between the methyl groups at C-17 and C-20 $0^{5,7-9}$. However, whilst the newly described (+)-15-hydroxy3-cleroden-2-one (1) is a typical cis-cledorane, (-)-hardiwickiic acid (2) possesses a trans-clerodane configuration. In conclusion, the occurrence of compounds $\mathbf{1}, \mathbf{2}, \mathbf{3}$ and $\mathbf{4}$ in $C$. sylvestris reveals the ability of this species in biosynthesize both cis and trans-clerodanes as it is common in other plant species as Adelanthus lindenbergianus (Adelhantaceae) ${ }^{13}$ and Grangea maderaspatana (Asteraceae) ${ }^{18}$.

\section{ACKNOWLEDGMENTS}

The authors are grateful to the Fundação de Amparo à Pesquisa do Estado de São Paulo (FAPESP), Conselho Nacional de Desenvolvimento Científico e Tecnológico (CNPq), Coordenação de Aperfeiçoamento de Pessoal de Nível Superior (CAPES) and the Instituto Florestal da Secretaria do Meio Ambiente do Estado de São Paulo for support of the project; Laboratório de Espectrometria de Massas da Faculdade de Ciências Farmacêuticas da Universidade de São Paulo, campus de Ribeirão Preto for MS determination. 
A. G. dos Santos and C. C. Perez thank FAPESP, and A. G. Tininis thanks CAPES, for the provision of respective scholarships.

\section{REFERENCES}

1. Basile, A. C.; Sertiè, J. A. A.; Panizza, S.; Oshiro, T. T.; Azzolini, C. A.; J. Ethnopharmacology 1990, 30, 185; Correa, M. P.; Dicionário das Plantas Úteis do Brasil e das Exóticas Cultivadas, Ministério da Agricultura/IBDF: Brasília, 1975; Lorenzi, H.; Árvores Brasileiras, Plantarum: São Paulo, 1992.

2. Borges, M. H.; Soares A. M.; Rodrigues, V. M.; Andrião-Escarso, S. H.; Diniz, H.; Hamaguchi, A.; Quintero, A.; Lizano, S.; Gutiérrez, J. M.; Giglio, J. R.; Homsi-Brandeburgo, M. I.; Comp. Biochem. Physiol., Part B: Biochem. Mol. Biol. 2000, 127, 21.

3. Ruppelt, B. M.; Gonçalves, L. C.; Pereira, N. A.; Revista Brasileira de Farmácia 1990, 71, 57.

4. Sertiè, J. A. A.; Carvalho, J. C. T.; Panizza, S.; Pharm. Biol. 2000, 38, 112.

5. Itokawa, H.; Totsuka, N.; Morita, H.; Takeya, K.; Iitaka, Y.; Schenkel, E. P.; Motidome, M.; Chemical and Pharmaceutical Bulletin 1990, 38, 3384.

6. Khan, M. R.; Gray, A. I.; Sadler, I. H.; Waterman, P. G.; Phytochemistry 1990, 29, 3591; Gibbons, S.; Gray, A. I.; Waterman, P. G.; Phytochemistry 1996, 41, 635; Hunter, M. S.; Corley, D. G.; Carron, C. P.; Rowold, E.; Kilpatrick, B. F.; Durley, R. C.; J. Nat. Prod. 1997, 60, 894; Beutler, J. A.; McCall, K. L.; Herbert, K., Herald, D. L.; Pettit, G. R.; Johnson, T.; Shoemaker, R. H.; Boyd, M. R.; J. Nat. Prod. 2000, 63, 657.
7. Morita, H.; Nakayama, M.; Kojima, H.; Takeya, K.; Itokawa, H.; Schenkel, E. P.; Motidome, M.; Chemical and Pharmaceutical Bulletin 1991, 39, 693.

8. Carvalho, P. R. F.; Furlan, M.; Young, M. C. M.; Kingston, D. G. I.; Bolzani, V. da S.; Phytochemistry 1998, 49, 1659.

9. Oberlies, N. H.; Burgess, J. P.; Navarro, H. A.; Pinos, R. E.; Fairchild, C. R.; Peterson, R. W.; Soejarto, D. D.; Farnsworth, N. R.; Kinghorn, A. D.; Wani, M. C.; Wall, M. E.; J. Nat. Prod. 2002, 65, 95.

10. Hasan, C. M.; Healey, T. M.; Waterman, P. G.; Phytochemistry 1982, 21, 1365.

11. Jolad, S. D.; Hoffmann, J. J.; Schram, K. H.; Cole, J. R.; J. Org. Chem. 1982, 47, 1356.

12. Billet, D.; Durgeat, M.; Heitz, S.; Brouard, J. P.; Ahond, A.; Tetrahedron Lett. 1976, 32, 2773.

13. Bläs, B.; Zapp, J.; Becker, H.; Phytochemistry 2004, 65, 127.

14. De Pascual, T. J.; Gonzalez, J.; Herrero, J. A.; Bermejo, F.; Anales de Quimica 1978, 74, 531.

15. Misra, R.; Pandey, R. C.; Dev, S.; Tetrahedron Lett. 1964, 49, 3751; Luzbetak, D. J.; Torrance, S. J.; Hoffman, J. J.; Cole, J. R.; J. Nat. Prod. 1979, 42, 315; Heymann, H.; Tezuka, Y.; Kikuchi, T.; Supriyatna, S.; Chemical and Pharmaceutical Bulletin 1994, 42, 1202; Bandara, B. M. R.; Wimalasiri, W. R.; Bandara, K. A. N. P.; Planta Med. 1987, 6, 575.

16. Misra, R.; Pandey, R. C.; Dev, S.; Tetrahedron Lett. 1968, 22, 2681.

17. Cascon, V.; Benjamin, G.; Phytochemistry 2000, 55, 773; Bigham, A. K.; Munro, T. A.; Rizzacasa, M. A.; Robins-Browne, R.; J. Nat. Prod. 2003. $66,1242$.

18. Singh, P.; Jain, S.; Jakupovic, J.; Phytochemistry 1988, 27, 1537. 